Working Paper

Business Economic Series

W . 10-06

ISSN 1989-8843
Instituto sobre Desarrollo

Empresarial

Carmen Vidal Ballester.

Universidad Carlos III de Madrid

C/ Madrid, 126

28903 Gelale Madrid (5pain)

FAX (34-91) 6249607

\title{
Evolutionary Model of Existing Competition and Voluntary Disclosure
}

\section{First Draft October 2010}

\author{
Manuel Núñez-Nickel ${ }^{\mathrm{a}^{*}}$, Susana Gago Rodríguez ${ }^{\mathrm{b}}$
}

a manuel.nunez@uc3m.es, Department of Business Administration, University Carlos III de Madrid, 126 Calle Madrid, 28903 Getafe, Madrid (Spain)

${ }^{\mathrm{b}}$ susana.gago@uc3m.es, Department of Business Administration, University Carlos III de Madrid, 126 Calle Madrid, 28903 Getafe, Madrid (Spain)

*Corresponding author: Tel: 34-916-245-846 Fax: 34-916-249-607 


\title{
Evolutionary Model of Existing Competition and Voluntary Disclosure
}

\begin{abstract}
We analyze how, in the absence of capital market incentives, the influence of existing competition on voluntary disclosure is an evolving process which has a non-monotonic design. The progressive capability of rivals to forecast significant information and the increasing losses of abnormal profits during the industry life cycle generate fears and incentives that change the sign of the relationship between competition and the probability of voluntary disclosure throughout the industry's development. We support this new design empirically by applying a semi-parametric Cox model to 28 years of archival data for the entire Spanish newspaper sector. We also find that the best fitting model is the first harmonic of a Fourier series.
\end{abstract}

Keywords: Competition; Voluntary disclosure; Fourier series; Cox model. 


\section{Evolutionary Model of Existing Competition and Voluntary Disclosure}

\section{Introduction}

To date, the relationship between competition and voluntary disclosure is an open question with different and contradictory theoretical answers (Verrecchia and Weber, 2006, p. 796). From an empirical focus, results do not help to eliminate irresolution since there are studies that have found significant support for each of the conflicting theoretical proposals (Dedman and Lennox, 2009, p. 211). Despite more than 40 years of research, there is no suitable explanation that makes such a diversity of results coherent.

The aim of this paper is to contribute a new eclectic explanation where the relationship between existing competition and voluntary disclosure is a dynamic process that evolves with the industry life cycle. The strategic importance of private information (Verrecchia, 1983), the necessity of informing rivals to avoid overproduction (Darrough and Stoughton, 1990), and the ability of competitors to forecast relevant information (Backer and McFarland, 1968) are the factors that modulate the sign of the slope between competition and voluntary disclosure. The successive changes in intensity of these strengths throughout a industry's lifetime produce a non-monotonic function.

As it was necessary to analyze the evolution of one industry, we chose to examine the decisions on voluntary disclosure of only one industry in-depth (all firms over an extended period of time). We selected the total population of Spanish newspapers from 1966 to 1993 as the institutional setting. We decided on this period because the entire sector was private during that period. This aspect neutralizes capital market incentives for both banks and stockholders (Dedman and 
Lennox, 2009, p. 211). Finally, we selected the newspaper industry since a firm's entire performance can be summarized in a single variable: circulation (the number of newspapers sold). This characteristic is fundamental for several reasons. First, this variable, in this sector, is the most important one for both producers (sellers) and clients (buyers) since it directly links the industry's two sources of revenue: newspaper sales and income from advertising, the price of which is established as a consequence of the number of newspapers sold. Second, we only need to study whether these firms disclose or withhold this figure; we do not need to analyze the number of items exhibited or the quality of the information revealed. An interesting additional advantage is that, as in other countries such as France and the U.S., this information is audited by an independent organism (OJD-Oficina de Justificación de la Difusión-“Office of Justification of the Diffusion"). All of these factors place us within the initial assumptions of Grossman (1981) and Milgrom (1981) by leaving out aspects such as the possibility of cheap-talk (Newman and Sansing, 1993; Gigler, 1994; Evans and Sridhar, 2002). Moreover, this population represents one of the first examples used to illustrate this controversy (Foster, 1986, p. 38).

This paper makes four contributions to existing literature. First, we challenge the theoretical status quo by showing that the pattern of existing competition's influence on the probability of voluntary disclosure is non-monotonic. Whereas previous literature discussed whether the relationship strictly increases or decreases, we find a theoretical explanation that changes the sign of this relation in accordance with the evolutionary phases the industry is in at a given time. In this way, the question, "Which influence is right?" should be exchanged for "Which phase is the industry in?". If we know the latter, we will be able to answer the former. Second, we confirm the relevance of the number of competitors as the measure of competition (Dedman and Lennox, 2009). Third, we regain the importance of archival documents in estimating competition. Thus, we can specialize and analyze the diverse dimensions within the concept of competition in much 
greater depth. And finally, we prove that these results are robust since we use panel data from 28 years in the same industry which removes the possibility of spurious results by cross analysis through sectors.

Section 2 presents previous literature within this research stream. Section 3 then deals with our particular view of the phenomenon as theoretical background, Section 4 describes the institutional setting and the data base, Section 5 specifies variable measurement and empirical models, Section 6 develops the results and finally, we present our conclusions.

\section{Related literature}

Figure 1 displays all papers that have, to our knowledge, studied the influence of competition on voluntary disclosure of information. Since "Proprietary Costs", when produced by the competition, was the first intuition that linked both variables, the central circle represents this hypothesis (Backer and McFarland, 1968; Mautz, 1968), that is, the negative relationship between competition and voluntary disclosure (Verrecchia, 1983). We divide the figure into three sets of papers: theoretical papers are gathered on the lower right, econometric tests on the left, and surveys or interviews on the upper right.

The direction of the arrows indicates ratification of the central hypothesis if it points towards the central circle or its refutation if the arrow points away. Among the papers that refute the proprietary cost hypothesis, we include the significant positive relationship between competition and voluntary disclosure (most papers), and the absence of significance (e.g. Botosan and Harris, 2000; Berger and Hann, 2007 and Li, 2010) as it also argues against the initial negative relationship. 


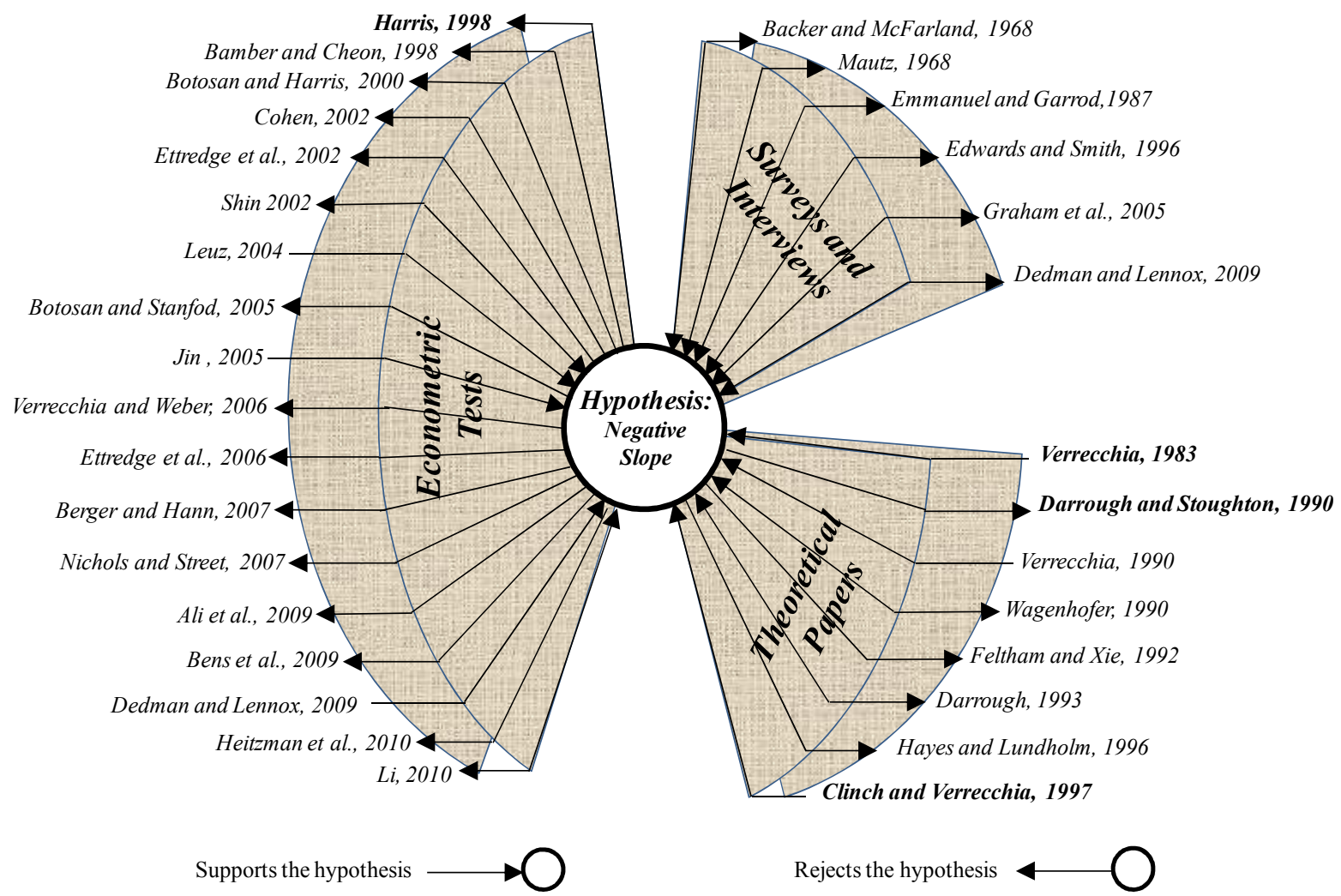

Fig. 1. Review of Literature

Additionally, there are some arrows which point in both directions (e.g. Backer and McFarland, 1968; Wagenhofer, 1990; Darrough, 1993; Shin, 2002 and Li, 2009). These studies both ratify and refute the proprietary cost hypothesis depending on the diverse circumstances that each paper deals with, or according to the kind of test used, sometimes there is significant support in favor, and other times against.

To summarize the state of the art in this research source, there are eight theoretical works, although only three are completely in favor of the proprietary cost hypothesis. There are also 18 econometric tests, but only three are clearly in favor. The majority of the remaining 15 find evidence against while a few have mixed results. Finally, there are six papers that develop surveys or interviews with evidence in both directions. As a consequence, the only evidence is 
that there is no clear theoretical or empirical support for "Proprietary Costs" hypothesis or for its alternative.

The many nuances of this research line are beyond the scope of our work. However, there are two groups of articles which are the cornerstones of this research. First of all, the four papers in bold in Figure 1 (and later included afterwards in Figure 2): three are theoretical (Verrecchia, 1983; Darrough and Stoughton, 1990; Clich and Verrecchia, 1997) and one is a test (Harris, 1998). In a static context, these four papers could all seem to be against. However, when we consider a dynamic and evolving process, they are actually defining the sector's progress in relation to the influence of competition on voluntary disclosure. The second group of papers includes surveys and interviews (Backer and McFarland, 1968; Mautz, 1968; Emmanuel and Garrod, 1987; Edwards and Smith, 1996; Graham et al., 2005; Dedman and Lennox, 2009). The results that they get are very similar. Most managers disagree or strongly disagree with disclosing information, in line with the proprietary cost hypothesis. However, in all cases, they also find evidence that some managers agree or strongly agree with disclosing more information or at minimum, they are indifferent. That is what led us to use arrows in both directions to illustrate them. Despite the fact that they always speak in favor of the central hypothesis, or to be more precise, they carry out research to prove the existence of proprietary cost, nonetheless, they also find people that disagree with this hypothesis. Table 1 summarizes these results extracted from the surveys: 
Table 1

Attitude towards disclosing information

\begin{tabular}{l|c|c|c|c|c|} 
& $\begin{array}{c}\text { Strongly } \\
\text { Agree }\end{array}$ & Agree & Indifferent & Disagree & $\begin{array}{c}\text { Strongly } \\
\text { Disagree }\end{array}$ \\
\hline Backer and McFarland, 1968 & $16.4 \%$ & $5.9 \%$ & & $23.8 \%$ & $53.7 \%$ \\
\hline Mautz, 1968 & $8.1 \%$ & $25.1 \%$ & $6.7 \%$ & $27.6 \%$ & $32.5 \%$ \\
\hline Edwards and Smith, 1996 (Before SSAP25) & $28 \%$ & $8 \%$ & $9 \%$ & $26 \%$ & $29 \%$ \\
\hline Edwards and Smith, 1996 (After SSAP25) & $31 \%$ & \multicolumn{2}{|c|}{$27 \%$} & $17 \%$ & $15 \%$ \\
\hline Graham et al., 2005 & \multicolumn{2}{|c|}{$24.8 \%$} & $16.4 \%$ & \multicolumn{2}{c|}{$58.8 \%$} \\
\hline Dedman and Lennox, 2009 & \multicolumn{3}{|c|}{$17.5 \%$} & \multicolumn{2}{c|}{82.5} \\
\hline
\end{tabular}

The table reports the summary of percentages in relation to the different attitudes towards voluntary disclosure that the surveys reveal. Some cells are combined since all authors do not explain their results in detail.

In light of this report, although there are few studies, it is difficult to imagine that managers can have such opposing opinions regarding the same phenomenon. We believe that the real explanation is they are looking at different events; that is they see and describe the circumstances of their own sectors at their different stages.

\section{Theoretical background}

The evolution of the industry life cycle in any sector means the simultaneous occurrence of two different events affecting private disclosure: a gradual loss of abnormal profits (Harris, 1998); and a progressive ability to anticipate important data without the necessity for firms to disclose confidential information (Backer and McFarland, 1968, p. 84-85; Emmanuel and Garrod, 1987, p. 237). Both factors generate varying degrees of incentives and fears at different stages of the sector's maturity, altering trends in relation to the probability of voluntary disclosure. 


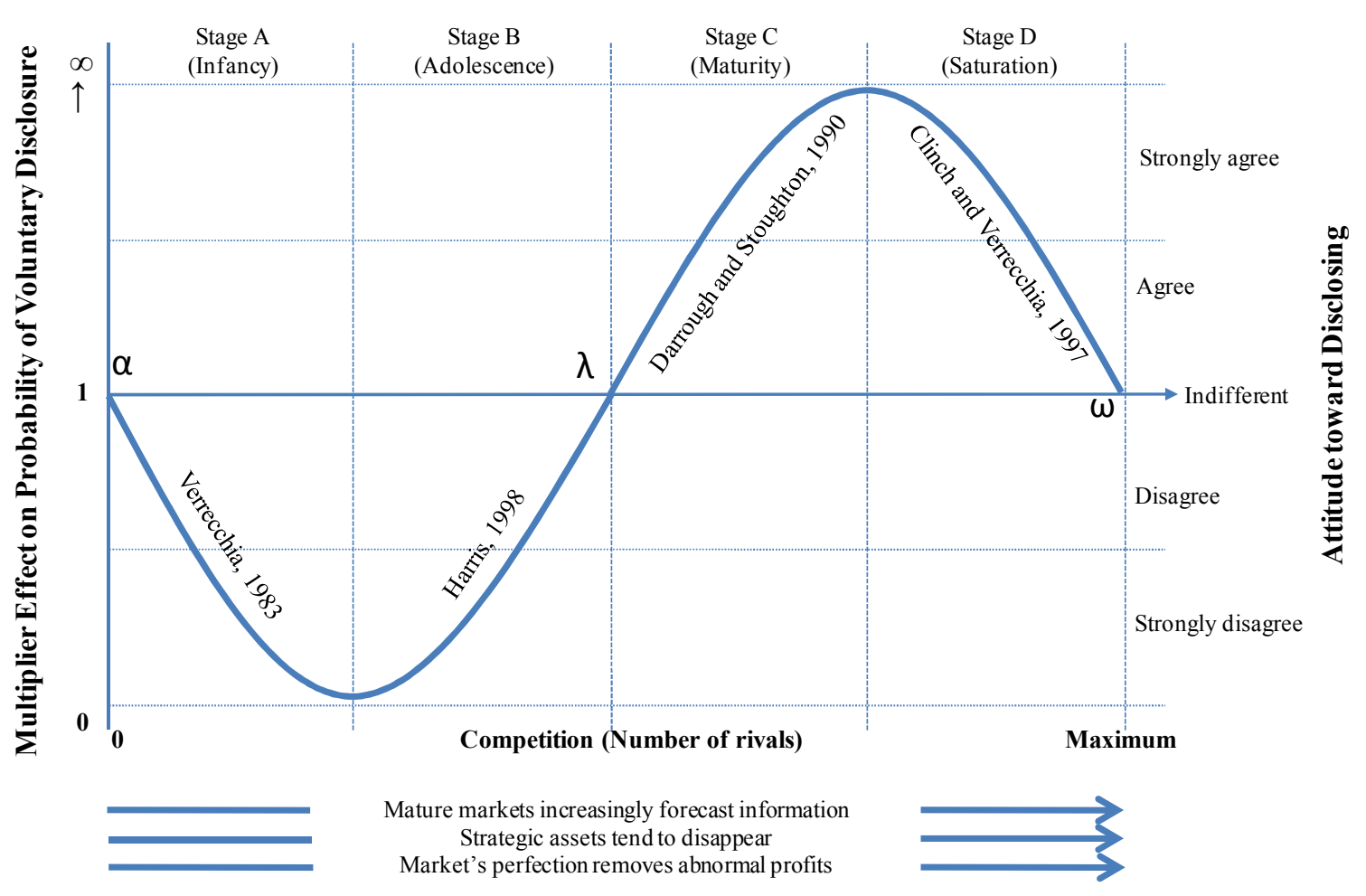

Fig. 2. Theoretical Summary. Evolution of the relationship between existing competition and the probability of voluntary disclosure

Figure 2 outlines our theoretical reasoning. On the x-axis, we represent real competition with the number of rivals existing at a given point. The competition of an industry evolved from its birth through its maturity (Klepper, 1996): the number of producers grows firstly because when the industry is new there are a lot of entry competitors, hitting the highest point, after which there could be a decline in the number of competitors because of exists overtakes entry. We consider this to be the evolution of the industry. The y-axis depicts attitude towards the disclosure of private information. On the right side, we use the common terminology used by the most representative surveys to date (e.g. Backer and McFarland, 1968, p. 78; Graham et al., 2005, p. 60; Mautz, 1968, p. 196). However, on the left, we convert these terms to a multiplier model ${ }^{1}$

\footnotetext{
${ }^{1}$ We choose a multiplicative relationship between competition and the probability of voluntary disclosure, to directly test our theoretical argument with a standard econometric model: Cox Proportional Hazard Model. As explained below, this model has
} 
where the value of 1 represents indifference to showing information or not, thus a factor of one has no effect. However, values greater than 1 increment the probability of voluntary disclosure, and values smaller than 1 reduce this same probability. Bearing this composition in mind, Figure 2 also shows four different stages in the total evolution of the sector. The particular reasoning behind stages $\mathrm{A}, \mathrm{B}, \mathrm{C}$ and $\mathrm{D}$ is that we consider the relationship between competition and the probability of voluntary disclosure to be a continuous function with no rupture points.

Stage A (Infancy): The sector is at its beginning. At the first point (Point $\alpha$ in Figure 2) there is no competition, that is, the number of rivals is equal to zero; we are at the first point of indifference. If a factor does not exist, then it has no influence, either positive or negative. The newness of the sector impedes competitors from obtaining private information easily since few innovations are able to generate important advantages, and as a consequence, abnormal profits. Competition is minimal, but releasing private news can eliminate these extra profits since it is the only source of information. Under these conditions, producers need to protect meaningful information, and this quickly reduces the probability of their releasing private information as a consequence of high proprietary costs (Verrecchia, 1983).

Stage B (Adolescence): The previous situation continues to decrease the probability of voluntary disclosure, but strategic assets tend to disappear (Bamber and Cheon, 1998). Private information continues to be important, but less and less relevant in relation to the increment in competition and, as a consequence, the desire to protect it flags (Harris 1998). Our function reaches a minimum from which producers continue to hide strategic information, but with decreasing strength. In a similar proportion to the reduction of abnormal profits, managers lose enthusiasm and tend towards indifference (Point $\lambda$ in Figure 2).

several advantages to handle this specific problem. However, with no loss of generality, we would get identical conclusions with additive alternatives. 
Stage C (Maturity): Despite the fact that stages B and C may seem similar, there is a fundamental difference: from Point $\lambda$, firms surpass indifference, and voluntarily begin to release information. It is one thing to give up hiding strategic information because it is not so important and quite another to actively inform the competition of the market situation. In spite of the competitors' increasing capability to forecast relevant information in the sector over the three stages, the components of the sector must still release private information regarding the generalized absence of good news and thereby avoid overproduction (Darrough and Stoughton, 1990; Feltham and Xie, 1992).

Stage D (Saturation): Bad news is generalized since competition is at a maximum and there are no extra profits. However, the capability of the competitors to learn about new information reaches its highest level. The competition tends to know everything or almost everything when the sector is at maximum maturity without the necessity of releasing private information (Backer and McFarland, 1968, p. 84-85; Emmanuel and Garrod, 1987, p. 237). If new releases do not contribute new information because the competitors are able to anticipate everything, the producers do not have any incentive to continue informing and, as a consequence, they go back to indifference at Point $\omega$ in Figure 2. This last relationship again generates an inverse influence between competition and the probability of voluntary disclosure (Clinch and Verrecchia, 1997)

\section{Research setting}

We chose to analyze the disclosure policies of the daily newspaper publishing industry in Spain in the period of 1966-1993. The database is composed of the information of 276 newspapers gathered from three different sources. The first is the Registry of Journalistic Firms (Registro de Empresas Periodisticas), which was created by the Law of Press and Printing (Ley de Prensa e Imprenta) on March 18, 1966. This law mandates the recording of any newspaper 
that is in circulation in Spain from this date. The second source is the General Mass Media Guide (Guía General de Medios de Comunicación), a publication in which newspapers advertise their price lists. Each of these sources confirms the information of the others. They provide organizational and individual information for each publication which we have used to build the variables included in our tests: title, founding date, the exact date they ceased operations, content, coverage, location, language, etc. The final source of data is the reports produced by the independent, non-profit newspaper association, the OJD (Oficina para la Justification de la Difusión). Similar to the Audit Bureau of Circulations in the USA or the Office de Justification des Tirages in France, the function of this association is to audit the number of newspapers sold (circulation). Through the same Law of Press and Printing, the OJD was created to audit the circulation of any newspaper that requests it. In exchange, it receives a small fee, proportional to each firm's turnover. Newspapers are not compelled to be audited by the OJD; it is completely voluntary. However, if this service is requested, the newspaper must accept a rigorous and extensive examination of any functional, operational or accounting processes required by the OJD in order to validate the circulation figure certified by the OJD. This is important to our research because the Spanish newspaper industry uses the OJD as its means of voluntary disclosure of its most relevant performance figure: circulation or number of newspapers sold.

There are several advantages derived from studying this industry. First, its simplicity avoids the influence of any odd factors or those which are difficult to control. This absence of complexity affects several aspects. First, these firms have only one main product, the newspaper, and every firm offers only one newspaper in the period we have analyzed. Newspapers are almost perfectly substitutive: prices for readers are similar throughout the entire industry, and for any given period. Due to the fact that newspapers comprise several specializations, such as content or location, they can be controlled for in tests. Second, all firms belong to the same industry, the 
same country, and are relatively isolated from the global foreign market as a consequence of the particular languages that exist in Spain (Basque, Castilian, Catalonian, and Galician). Third, firms only need to disclose one figure, the circulation or number of newspapers sold. Knowing circulation figures, anybody within this industry could easily approximate costs and revenues since organization and technology are simple and, in any case, very similar. This simplifies the analysis of voluntary disclosure considerably since we do not need to analyze how much information firms have, its quality, or its veracity. We only need to analyze whether the firm discloses or withholds circulation figures; if it chooses to reveal the information it is audited by the OJD. Third, this industry is within Milgrom's (1981) and Grossman's (1981) main assumption of full disclosure equilibrium. Clients (buyers) need to know circulation figures (synonymous with a newspaper's quality) since the more newspapers sold, the more readers acquire the newspaper and consequently, see the advertisements. Actually, firms charge advertising prices (theoretically) based upon circulation or number of readers that will see the advertisements. That means that if a firm withholds this information, it is hiding its "quality" from clients. And finally, in this analysis, the stock market does not exert any influence on the firms. We have chosen a period during which these firms did not yet quote on the stock market (Dedman and Lennox, 2009). The main motive is to neutralize what we consider a cornerstone effect within this line of research. It is clear that stockholders need information about a firm's performance. In the newspaper industry, due to its idiosyncrasy, sales figures are not only interesting for clients, but also for others interested in accounting information, including stockholders. With this, we recognize that firms could have sources of motivation for disclosing other than the aforementioned, and that they could influence their decision to disclose, particularly when considering the influence of the financial market. 


\section{Research design}

\subsection{Econometric choices}

Given the sophisticated pattern, the analysis compelled us to find an econometric model whose endogenous variable is a probability that evolves over time (in relation to the sector), and one that is sufficiently versatile to adjust to any new functional design, but without including restrictions that force results in any way. In other words, we need a model that permits the analysis of several firms over time and the inclusion of non-parametric methodology. We think that the Cox proportional hazard model fulfills both conditions for the following reasons (Lawless, 2003). 1. It lets us estimate the hazard rate $h(t)$ or instantaneous rate of voluntary disclosure at time $t$, where $t$ is the time when the newspaper could first release circulation information until the time that it actually does so.

$$
h(t)=\lim _{\Delta t \rightarrow 0} \frac{\operatorname{Pr}(t \leq T \varsigma t+\Delta t / T \geq t)}{\Delta t}
$$

Thus, we have an econometric model whose endogenous variable is the probability of voluntary disclosure, and moreover, this variable evolves over time. 2. By itself, it is a semi-parametric model that allows us to estimate the design of the influence without specifying the distribution of the function. 3. However, it also permits us to include nonparametric methodology, avoiding any restriction on the functional relation between exogenous and endogenous variables (Huang, 1999). In this case, we have chosen Fourier series, although in our sensibility analysis, we have used other polynomial splines. 4. Finally, this model also lets us include and analyze the evolution of exogenous variables such as panel data methodology over time. 
To summarize, this model is appropriate to exploit our panel data base to the utmost, but, at the same time, we can use nonparametric methodology in order to avoid any suspicions that force the final design of our tests.

Its general expression is:

$$
h(t)=h_{0}(t) \cdot \exp (x(t) \gamma)
$$

Where $\mathrm{h}_{0}(\mathrm{t})$ is the baseline hazard function, although it is not necessary to define it for the Cox model (it is not estimated). "Exp" is the exponential transformation since $h(t)$ always needs to be positive since it is a probability; $\mathrm{x}$ is the vector of variables: exogenous, such as types of competition or its transformation, and all other control variables. And $\gamma$ is the vector of regression coefficients to estimate.

To analyze the functional relationship between competition and probability of voluntary disclosure, we choose to include the nonparametric polynomial approximation by Fourier series within the Cox model, since any finite function can be approximated by an infinite summation with this form:

$\mathrm{f}(\mathrm{x})=\sum_{k=0}^{\infty}\left[\alpha_{k} \sin (k \cdot x)+\beta_{k} \cos (k \cdot x)\right]$

In this way, each harmonic, or the addition of the sine plus the cosine for each value of $\mathrm{k}$, would be a more sophisticated approach to the objective function.

Finally, including this kind of nonparametric analysis within the Cox model has another added advantage in relation to other nonparametric methodologies because we can also calculate a likelihood ratio test as a whole for the set of harmonics in each model. In this way, we will not only see the design of our function for our particular data as in other nonparametric methodologies, but we can also prove if the fit is more significant than for the standard parametric approximations in spite of including a greater number of transformations of the same variable . 
As we do not have censored data, we have used maximum likelihood from Stata 11 (StataCorp. 2009) to estimate each parameter.

\subsection{Variables}

\section{Endogenous variable ( $t$ )}

As explained above, our endogenous variable is time from the moment in which the firm can release circulation information until the moment when it decides to actually do so. Hence, our endogenous variable measures delay of engagement on voluntary disclosure. The utilization of duration models directly permits us to study the influence between exogenous variables and probability of voluntary disclosure by means of hazard rate: $h(t)$, as it appraises the effect of our explanatory variable, the delay in disclosing, on the hazard or risk of voluntary disclosure (Lawless, 2003).

Exogenous variables (Competition)

Competition is not a unitary concept; it can be measured from several variables (Edwards and Smith, 1996, p. 158). Although researchers have typically used two different measures in this research line, concentration indexes and/or speed of abnormal profit adjustment (e.g. Harris, 1998; Botosan and Harris, 2000; Botosan and Stanford, 2005; Nichols and Street, 2007), we have chosen the number of rivals competing in each period (used, for example, by Jin, 2005). The first and main reason for our option is that Darrough and Stoughton (1990, p. 239) point to this particular variable as the one responsible for Verrecchia's findings (1983) on the opposed relationship between competition and voluntary disclosure. We propose that if we find that this variable in question also yields positive effects, it might also validate their reasoning without recurring to other variables which are more favorable to their arguments. Second, since we 
analyze the same industry over time rather than different industries, the increment of new rivals in each period is also a good proxy for degree of concentration since it would be the same as that of the previous period influenced by these new entries. Hence, the increase in competition can be better measured by the difference among the number of rivals over diverse periods. Third, using the number of rivals permits us to increase the level of analysis to examine different competitive scopes, breadth of firms' activities (Porter and Millar, 1998), or clusters or location of their business (Porter, 1998). We measure Broad Scope by the total number of newspapers that firms offer within the Spanish setting; Segment Scope by the number of newspapers with the same content (general, sport, and others.); Geographic Scope as the number of newspapers with the same reporting (national, regional, or local). And finally, with Location Scope, we measure the number of newspapers that are competing in the same autonomous community, not at the national level. Spain has 19 autonomous communities with political and administrative attributes that are similar to a federal state. Finally, as we have chosen to examine the period where the firms did not quote on the stock market, we cannot calculate the speed of abnormal profit adjustment.

\section{Control Variables}

We cannot calculate concentration indexes since the number of newspapers sold by each firm not revealed through the OJD is not available. As a consequence, we are not able to calculate the total quantity of newspapers sold according to the different scopes. However, we try to control Market Breadth in each period through the population of literate people older than 16 years (in millions). We also measure the evolution of the Spanish economy by the Gross National Product in milliard (billion) pesetas (Spanish currency prior to the euro). Finally, we also include as an external control variable, the Herding Effect (e.g. Dye and Sridhar, 1995; Arya and Mittendorf, 2005; Mensah and Yang, 2008) since it is possible that firms disclose information as 
a consequence of previous releases within the same industry. We have measured this effect by the number of newspapers that have disclosed in the previous period.

Organizational Control Variables:

As particular characteristics of this kind of firm, we have included Age calculated by the

number of years of the newspaper's existence since its foundation, whether its content is General (by giving a value of 1 if the newspaper has general content and 0 if otherwise), Sport ( 1 if the newspaper has only sport content, and 0 if otherwise), whether its coverage is National (1 if national, 0 if otherwise), Regional (1 if regional, 0 if otherwise) and Family Firm (equal to 1 when the newspaper is owned by a family, and 0 if otherwise).

Finally, as a measure of firms' performance, we include the estimation of the Probability of Failure (hazard rate) in any period for every firm. As in the aforementioned and like other organizational variables, we have not used usual performance measures such as sales or profits. However, we analyze panel data and can estimate a hazard rate where the event is the time from the firm's beginning to its demise, the same as with our endogenous variable, but changing the phenomenon to be estimated.

\section{Empirical results}

\subsection{Descriptive statistics}

Table 2 displays means, standard deviations and range of all variables used in tests.

\section{Table 2}

Descriptive statistics 


\begin{tabular}{lccccc}
\hline \multicolumn{1}{c}{ Variable } & Observations & Mean & $\begin{array}{c}\text { Standard } \\
\text { Deviation }\end{array}$ & Maximum Minimum \\
\hline 1 Competitive Broad Scope & 13,903 & 123.347 & 8.531 & 109 & 145 \\
2 Competitive Segment Scope & 13,903 & 104.320 & 30.289 & 1 & 132 \\
3 Competitive Geographic Scope & 13,903 & 58.580 & 25.524 & 12 & 92 \\
4 Competitive Location Scope & 13,903 & 10.906 & 5.918 & 1 & 26 \\
5 Market Breadth & 13,903 & 27319 & 2.501 .855 & 23848.67 & 31272.44 \\
6 Gross National Product & 13,903 & 37702.51 & 8.716 .672 & 20876.6 & 51625.6 \\
7 Herding Effect & 13,903 & 62,462 & 15,731 & 5 & 90 \\
8 Age & 13,903 & 45.644 & 34.507 & 0.001 & 191.663 \\
9 General Content & 13,805 & 0.921 & 0.269 & 0 & 1 \\
10 Sport Content & 13,805 & 0.035 & 0.185 & 0 & 1 \\
11 National Coverage & 13,571 & 0.119 & 0.324 & 0 & 1 \\
12 Regional Coverage & 13,571 & 0.265 & 0.441 & 0 & 1 \\
13 Family Firm & 13,852 & 0.020 & 0.142 & 0 & 1 \\
14 Probability of Failure & 13,510 & 0.032 & 0.082 & 0.000 & 0.924 \\
\hline
\end{tabular}

Table 3 shows the correlations (Pearson and Spearman) between variables, two by two. The differences regarding correlations between the different types of competition that we have measured stand out. We can see that Broad Scope has a high interrelation with Segment Scope (in the Spearman correlation, in relation to Pearson it is considerably smaller). However, it is almost uncorrelated with Geographic or Location Scopes. Definitively, with these data, we can assert that, as indicated by Edwards and Smith (1996) the concept of competition is a multidimensional phenomenon, and also that it is difficult to find variables with which it can be dealt.

Table 3

Pearson and Spearman Correlations 


\begin{tabular}{|c|c|c|c|c|c|c|c|c|c|c|c|c|c|c|}
\hline Variables & 1 & 2 & 3 & 4 & 5 & 6 & 7 & 8 & 9 & 10 & 11 & 12 & 13 & 14 \\
\hline 1 Competitive Broad Scope & & 0.8350 & 0.6159 & 0.2904 & 0.1522 & 0.2627 & 0.2046 & -0.0567 & -0.0033 & -0.0103 & -0.0010 & -0.0161 & -0.0251 & -0.0600 \\
\hline 2 competitive Segment Scope & 0.8257 & & 0.6801 & 0.3232 & 0.2490 & 0.3208 & 0.2380 & -0.0814 & -0.0543 & 0.1088 & 0.0377 & -0.0195 & -0.0216 & -0.0208 \\
\hline 3 Competitive Geographic Scope & 0.5161 & 0.5606 & & 0.3306 & 0.4629 & 0.4999 & 0.4417 & -0.1072 & 0.0013 & -0.0216 & -0.0486 & -0.0831 & -0.0372 & 0.1024 \\
\hline 4 Competitive Location Scope & 0.2724 & 0.2865 & 0.3021 & & 0.2326 & 0.2518 & 0.2238 & -0.1053 & 0.0000 & -0.0142 & 0.0423 & 0.0154 & -0.0842 & 0.0942 \\
\hline 5 Market Breadth & 0.0754 & 0.1086 & 0.3807 & 0.2289 & & 0.9509 & 0.8609 & -0.0560 & -0.0367 & -0.0009 & 0.0076 & 0.0287 & 0.0192 & 0.1531 \\
\hline 6 Gross National Product & 0.0940 & 0.1127 & 0.3895 & 0.2335 & 0.9805 & & 0.9202 & -0.0487 & -0.0388 & -0.0000 & 0.0095 & 0.0243 & 0.0175 & 0.1305 \\
\hline 7 Herding Effect & 0.1038 & 0.1270 & 0.3931 & 0.2296 & 0.9478 & 0.9644 & & -0.0271 & -0.0411 & 0.0077 & 0.0162 & 0.0274 & 0.0172 & 0.1528 \\
\hline 8 Age & -0.0628 & -0.0807 & -0.1088 & -0.1202 & -0.0649 & -0.0626 & -0.0579 & & 0.1512 & -0.0691 & -0.0533 & 0.2502 & 0.1980 & -0.2064 \\
\hline 9 General Content & 0.0002 & -0.0155 & 0.0004 & 0.0014 & -0.0381 & -0.0398 & -0.0391 & 0.1511 & & -0.6606 & -0.5209 & 0.1394 & 0.0684 & -0.0078 \\
\hline 10 Sport Content & -0.0106 & 0.0698 & -0.0172 & -0.0176 & 0.0006 & 0.0020 & 0.0027 & -0.0664 & -0.6606 & & 0.4183 & -0.0623 & -0.0193 & -0.0040 \\
\hline 11 National Coverage & -0.0012 & 0.0217 & -0.0423 & 0.0413 & 0.0092 & 0.0106 & 0.0114 & -0.0462 & -0.5209 & 0.4183 & & -0.2241 & -0.1230 & -0.0016 \\
\hline 12 Regional Coverage & -0.0192 & -0.0166 & -0.0507 & 0.0205 & 0.0289 & 0.0287 & 0.0274 & 0.2208 & 0.1394 & -0.0623 & -0.2241 & & 0.1249 & -0.1065 \\
\hline 13 Family Firm & -0.0267 & -0.0216 & -0.0369 & -0.0867 & 0.0190 & 0.0196 & 0.0176 & 0.2119 & 0.0684 & -0.0193 & -0.1230 & 0.1249 & & -0.0801 \\
\hline 14 Probability of Failure & -0.0918 & -0.0480 & 0.2034 & 0.0471 & 0.1234 & 0.1146 & 0.1244 & -0.3462 & -0.0063 & -0.0188 & -0.0506 & -0.4115 & -0.1663 & \\
\hline
\end{tabular}

Table 3 presents the Pearson (Spearman) Correlations Above (Below) the Diagonal of the Matrix. Correlations $\geq$ $|0.02|$ significant at $1 \%$, Correlations $\geq|0.016|$ at $5 \%$ and Correlations $\geq|0.014|$ at $10 \%$

There are no other correlations that, by their magnitude, can cause multicolinearity problems, with the sole exception of Gross National Product and Market Breadth with a correlation of 0.95 . However, as both are control variables, falling outside our analysis, and given that taking them into consideration or not does not modify the final results, we have opted to include both of them in the different tests.

\subsection{Empirical tests}

Table 4 proves the suitability of the use of Cox's model in our tests. The proportional hazard assumption is the only prerequisite to validate the nonparametric Cox proportional hazard model. Its meaning is that every estimated parameter is unique over time. Table 4 exhibits an independent test for each variable and a global test for the whole model. It permits us to verify that the condition of proportionality is supported by our data in every one of the cases since each p-value is clearly greater than 0.05 .

Table 4

Proportional Hazard Assumption Test 


\begin{tabular}{lcccc}
\hline \multicolumn{1}{c}{ Variable } & $\rho$ (rho) Test & $\chi^{2}$ Test & $\begin{array}{c}\text { Degrees of } \\
\text { freedom }\end{array}$ & p-value \\
\hline 1 Competitive Broad Scope & -0.029 & 0.12 & 1 & 0.7345 \\
2 Competitive Segment Scope & 0.022 & 0.07 & 1 & 0.7962 \\
3 Competitive Geographic & 0.038 & 0.19 & 1 & 0.6622 \\
4 Competitive Location Scope & 0.024 & 0.06 & 1 & 0.8047 \\
5 Market Breadth & -0.009 & 0.01 & 1 & 0.9171 \\
6 Gross National Product & -0.021 & 0.06 & 1 & 0.8130 \\
7 Herding Effect & -0.014 & 0.02 & 1 & 0.8748 \\
8 Age & 0.02 & 0.06 & 1 & 0.8137 \\
9 General Content & -0.020 & 0.06 & 1 & 0.8086 \\
10 Sport Content & -0.050 & 0.35 & 1 & 0.5557 \\
11 National Coverage & 0.031 & 0.13 & 1 & 0.7216 \\
12 Regional Coverage & 0.029 & 0.11 & 1 & 0.7381 \\
13 Family Firm & -0.026 & 0.08 & 1 & 0.7795 \\
14 Probability of Failure & -0.020 & 0.03 & 1 & 0.8523 \\
\hline Global Test & & 2.80 & 32 & 10.000 \\
\hline
\end{tabular}

This table depicts the proportional hazard assumption test. The $\mathrm{H}_{0}$ of this test: there is a single ? over time (proportional); compared to $\mathrm{H}_{1}$ : of which there are several (not proportional). There is an independent test for each variable, and a global test for the complete model. On every line is the variable and four figures: 1. $\rho$ (rho) text or the statistic for testing individual covariates, 2. this $\rho$ (rho) text is not tabulated, but is asymptotically distributed as an $\chi^{2}$ random variable with 1 degree of freedom, 3. degrees of freedom and, finally, 4. the p-value for the $\chi^{2}$ texts.

Table 5 displays 9 econometric models. With the only exception of Model 1 where we only show the influences of the control variables, the others depict the influence of our four competition variables. Models 2, 4, 6 and 8 show the parameter and the significance level for these variables without any transformation as in previous literature. However, Models 3, 5, 7 and 9 exhibit the same but for the first harmonic of one Fourier series. In light of these results, we see how in any case when variables are not transformed; we do not find any level of significance. Nevertheless, in the other four models, in particular 7 and 9 (i.e. Geographic and Location Scopes), with only one harmonic, we obtain a high level of significance (p-value $<0.0141$ for Geographic Scope and p-value $<0.0000$ for Location Scope). For our data, it is clear that not all competition concepts fit the relationship with voluntary disclosure in the same way. In particular, Broad and Segment Scopes are clearly non-significant. However, it is also clear that there can be a great difference 
between using conventional methodology or one that is adapted to the requirements of this kind of phenomenon.

Table 5

Cox models regressions

\begin{tabular}{|c|c|c|c|c|c|c|c|c|c|}
\hline & Model 1 & Model 2 & Model 3 & Model 4 & Model 5 & Model 6 & Model 7 & Model 8 & Model 9 \\
\hline Variable/Competitive Scope & & Broad Scope & Broad Scope & Segment Scope & Segment Scope & Geographic Scope & Geographic Scope & Location Scope & Location Scope \\
\hline \multirow[t]{2}{*}{1 Competition (In Levels) } & & -0.018 & & -0.022 & & 0.007 & & 0.010 & \\
\hline & & $(-0.90)$ & & $(-1.04)$ & & $(0.23)$ & & $(0.57)$ & \\
\hline $2 \operatorname{Cos}($ Competition $)$ & & & -0.450 & & -0.028 & & $-0.411]$ & & -0.002 \\
\hline \multirow[t]{2}{*}{$3 \operatorname{Sin}($ Competition) } & & & 0.013 & & -0.232 & & $0.363^{\circ}$ & & $-0.548^{-3}$ \\
\hline & & & (2.79) & & $(0.68)$ & & $(8.52)$ & & (20.48) \\
\hline \multirow[t]{2}{*}{4 Market Breadth } & 0.000 & 0.000 & 0.000 & 0.000 & 0.000 & $0.000 *$ & $0.000 *$ & 0.000 & 0.000 \\
\hline & $(0.79)$ & $(0.83)$ & $(0.99)$ & $(0.87)$ & (1.19) & (1.03) & (2.11) & $(1.02)$ & $(1.35)$ \\
\hline \multirow{2}{*}{5 Gross National Product } & -0.000 & -0.000 & -0.000 & -0.000 & -0.000 & $-0.000 \ddagger$ & $-0.000 \%$ & -0.000 & -0.000 \\
\hline & $(-0.75)$ & $(-0.59)$ & $(-0.49)$ & $(-0.63)$ & $(-1.17)$ & $(-0.98)$ & $(-1.89)$ & $(-0.93)$ & $(-1.25)$ \\
\hline \multirow[t]{2}{*}{6 Herding Effect } & $0.052 * * *$ & $0.049 *$ & $0.038 *$ & $0.048 * * *$ & $0.055 * * *$ & $0.053 * * * *$ & $0.058 * * * *$ & $0.050 * * *$ & $0.053 * * *$ \\
\hline & (2.56) & $(3.08)$ & $(2.09)$ & (2.93) & $(3.27)$ & (3.11) & (3.68) & $(3.02)$ & $(3.04)$ \\
\hline \multirow[t]{2}{*}{7 Age } & 0.003 & 0.003 & 0.004 & 0.003 & 0.002 & 0.003 & 0.003 & 0.003 & 0.003 \\
\hline & $(0.72)$ & $(1.16)$ & (1.41) & (1.18) & $(0.93)$ & $(0.96)$ & $(1.21)$ & $(0.98)$ & $(1.04)$ \\
\hline \multirow[t]{2}{*}{8 General Content } & $1.514 * * *$ & $1.526^{* * *}$ & $1.478 * * *$ & $4.021 * * *$ & $1.560 * * *$ & $1.493 * * *$ & $1.549 * * *$ & $1.565 * * *$ & $1.448 * * *$ \\
\hline & $(2.78)$ & (3.30) & $(3.06)$ & $(1.61)$ & (3.07) & (3.96) & (3.10) & (3.17) & (3.26) \\
\hline \multirow[t]{2}{*}{9 Sport Content } & $1.172 *$ & $1.212 *$ & $1.169^{*}$ & $1.279 * *$ & $1.096 \ddagger$ & $1.144 * *$ & $1.397 * *$ & $1.195 *$ & $0.909 *$ \\
\hline & (1.78) & (2.63) & (2.48) & (2.63) & (1.78) & $(2.40)$ & $(2.64)$ & (2.53) & (2.17) \\
\hline \multirow[t]{2}{*}{10 National Coverage } & $0.582 *$ & $0.578 *$ & $0.591 *$ & $0.566 *$ & $0.559^{*}$ & $1.071^{* * *}$ & $0.978^{* * *}$ & $0.592 *$ & $0.888^{* * *}$ \\
\hline & $(1.64)$ & $(2.08)$ & $(2.26)$ & (2.07) & $(2.03)$ & $(0.50)$ & (3.10) & (2.17) & (3.17) \\
\hline \multirow[t]{2}{*}{11 Regional Coverage } & $-0.859 * * * *$ & $-0.855 * * * *$ & $-0.928 * * * *$ & $-0.854 * * * *$ & $-0.899 * * * *$ & -0.500 & -0.363 & $-0.865 * * * *$ & $-0.639^{* *}$ \\
\hline & $(-3.24)$ & $(-3.66)$ & $(-3.94)$ & $(-3.65)$ & $(-3.73)$ & $(-0.32)$ & $(-1.28)$ & $(-3.67)$ & $(-2.57)$ \\
\hline \multirow[t]{2}{*}{12 Family Firm } & -0.138 & -0.199 & -0.177 & -0.218 & -0.105 & -0.116 & -0.219 & -0.091 & -0.014 \\
\hline & $(-0.59)$ & $(-0.90)$ & $(-0.80)$ & $(-1.00)$ & $(-0.46)$ & $(-0.52)$ & $(-1.03)$ & $(-0.44)$ & $(-0.07)$ \\
\hline \multirow[t]{2}{*}{13 Probability of Failure } & $-1110.928^{* * * *}$ & $-1099.824 * * * *$ & $-1123.379 * * * *$ & $-1092,789 * * * *$ & $-1124.234 * * * *$ & $-11154.942^{* * * *}$ & $-1147.532^{* * * *}$ & $-1108.409^{* * * *}$ & $-1066.022 * * * *$ \\
\hline & $(-0.27)$ & $(-6.05)$ & $(-6.05)$ & $(-6.03)$ & $(-6.19)$ & $(-5.86)$ & $(-6.73)$ & $(-6.08)$ & $(-5.93)$ \\
\hline $\begin{array}{l}\text { Log Likelihood } \\
\end{array}$ & $-298.246 * * * *$ & $-297.779^{* * * *}$ & $-296.847 * * * *$ & $-297.577^{* * * * *}$ & $-297.905^{* * * *}$ & $-298.213^{* * * * *}$ & $-293.985^{* * * * *}$ & $-298.084 * * * *$ & $-288.007^{* * * * *}$ \\
\hline Global $\chi 2$ test & 142.03 & 148.04 & 147.77 & 148.94 & 144.53 & 150.99 & 149.97 & 144.57 & 144.10 \\
\hline (Degree of freedom) & 10 & 11 & 12 & 11 & 12 & 11 & 12 & 11 & 12 \\
\hline
\end{tabular}

This table shows the proportional hazard regressions of Cox's models. For each variable, maximum likelihood estimators are reported in the top row and $\chi 2$ test values (in parentheses) below each coefficient. $t . *$. **.***. and $* * * *$ indicate significance at $10 \% .5 \% .1 \% .0 .5 \%$. and $0.1 \%$ levels respectively. Estimated Models have the expression $\mathrm{h}(\mathrm{t})=\mathrm{h} 0(\mathrm{t}) \exp [\square \mathrm{X}(\mathrm{t})]$, where $\mathrm{h}(\mathrm{t})$ is the instant probability of voluntary disclosure (or Hazard Rate), $\mathrm{t}$ is the time when the event occurs (voluntary disclosure in our case), h0(t) is baseline hazard (undefined in Cox's model), $\square$ is the vector of estimated multiplicative coefficients shown in this table, X the vector of Fourier series of exogenous variables and the controls gathered in the first column.

Figure 3 plots the joint effect of each harmonic for every competition variable (Models 3, 5, 7 and 9). At first glance, and despite the different degree of significance between variables, we can see how, in any case, the relationship between competition and probability of voluntary disclosure is non-monotonic as we put forward in our theoretical background. However, when we only analyze the significant models, the design practically coincides with our entire theoretical development. Only in the case of Geographical Scope is there slight deviation from 
points $\alpha$ and $\omega$; as a consequence, they would not be placed in indifference as we deduced in the theoretical section. Nonetheless, when we analyze the clearly significant model (Model 9 with a p-value $<0.000$ ), we can see that the design coincides to the utmost detail. As a consequence, we consider that we have found support for the new evolutionary theoretical model and that the lack of sensitivity of other models is the consequence of error in measurement of different concepts of competition.

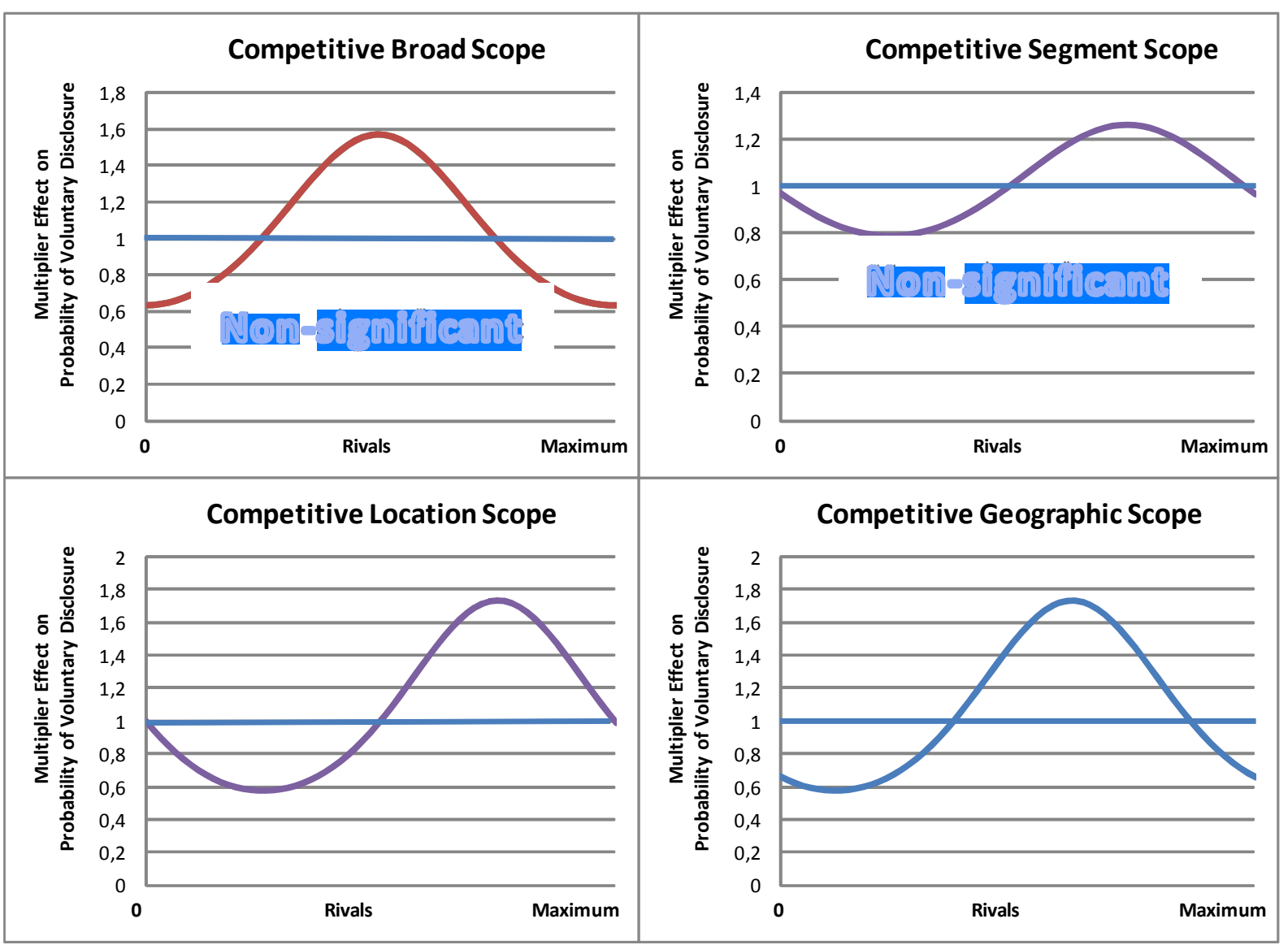

Fig. 3. Graph results. Each panel corresponds to one of the competition scopes calculated

The findings obtained for the control variables are robust. We can see how the same variables are significant or not for every model. An interesting aspect with possible implications within this research stream, and that, in our opinion, deserves further commentary is the fact that Herding Effect and Probability of Failure are highly significant in all cases. In relation to the former, it 
has a positive influence; that is, firms voluntarily disclose information because their rivals previously disclose the same type of information (Botosan and Harris, 2000, p. 333). The latter, the Probability of Failure, is also highly significant but negative with a very high coefficient. Our interpretation of this result is that, with the most minor bad news in relation to rivals, withholding information is the firm's response. It could be the proof of the level of agency problem within this sector.

\subsection{Sensitivity analysis}

In the previous section, we have shown the tests only with the first harmonic (i.e. the first addend of the Fourier series). We can deduce the motive from Table 6. In this table, we compare the likelihood test for each model that includes the different summations of harmonics, from the first to the seventh. We do not estimate more harmonics in the remaining models because estimations do not converge. If we analyze the set of models according to each competition variable, we can see how the most significant model (Location Scope) is attained with the first harmonic. That is, despite including more harmonics to come closer to the real function, the fit is progressively worse. Including more variables does not help us come closer to the design.

In relation to the second most significant (Geographic Scope), the result is the same up to the fifth harmonic, where the level of significance greatly improves. This is the main problem with non-parametric methodologies: we can fit our estimation to pass by every single point of the real function. Hence this case is a clear example that we can take even the outliers into consideration. We cannot forget that the transformation of this variable with 5 harmonics means including 10 more variables. Despite improvement in the level of significance, it cannot compare with the Location Scope Model. Finally, the other two models, despite including all possible harmonics, 
do not achieve a significance level lower than 0.05 . Therefore, we prefer to include the same number of harmonics (one, in our case) for each model in Table 5 in order to compare the degree of fit to the real function with the same conditions.

Table 6

Fourier series analysis

\begin{tabular}{|c|c|c|c|c|c|c|c|}
\hline Number of Harmonics (n) & 1 & 2 & 3 & 4 & 5 & 6 & 7 \\
\hline & \multicolumn{7}{|c|}{ Broad Scope } \\
\hline$x^{2}$ test & 2.7989 & 4.7295 & $11.1701+$ & 12.3029 & 13.5471 & 14.6025 & 17.9833 \\
\hline p-value & 0.2467 & 0.3161 & 0.0832 & 0.1381 & 0.1946 & 0.2638 & 0.2075 \\
\hline \multirow[t]{2}{*}{ (Degree of freedom) } & 2 & 4 & 6 & 8 & 10 & 12 & 14 \\
\hline & \multicolumn{7}{|c|}{ Segment Scope } \\
\hline$x^{2}$ test & 0.6802 & 5.5653 & 6.6017 & 11.2937 & 13.59762 & 17.5169 & $22.8066+$ \\
\hline p-value & 0.7110 & 0.6329 & 0.3592 & 0.1856 & 0.1921 & 0.1311 & 0.0634 \\
\hline \multirow[t]{2}{*}{ (Degree of freedom) } & 2 & 4 & 6 & 8 & 10 & 12 & 14 \\
\hline & \multicolumn{7}{|c|}{ Geographic Scope } \\
\hline$x^{2}$ test & $8.5225 *$ & $12.4391 *$ & $14.2600 *$ & $14.9982+$ & $26.2483 * * *$ & $29.1275^{* * *}$ & $30.7733 * *$ \\
\hline p-value & 0.0141 & 0.0143 & 0.0268 & 0.0591 & 0.0034 & 0.0037 & 0.0059 \\
\hline \multirow[t]{2}{*}{ (Degree of freedom) } & 2 & 4 & 6 & 8 & 10 & 12 & 14 \\
\hline & \multicolumn{7}{|c|}{ Location Scope } \\
\hline$x^{2}$ test & $20.4786 * * * *$ & $22.6099 * * * *$ & $23.2128 * * * *$ & $27.5763 * * * *$ & $29.4315 * * *$ & $31.7710^{* * *}$ & $38.4902 * * * *$ \\
\hline p-value & 0.0000 & 0.0001 & 0.0007 & 0.0005 & 0.0010 & 0.0015 & 0.0004 \\
\hline (Degree of freedom) & 2 & 4 & 6 & 8 & 10 & 12 & 14 \\
\hline
\end{tabular}

This table shows the likelihood rate test. The $\mathrm{H}_{0}$ of this test is: all coefficients of the Fourier series are not significant; compared to $\mathrm{H}_{1}$ : at least some are significant. Each panel corresponds to a different competition scope. In the first line, we see the number of harmonics included in each series. The degree of freedom coincides with the number of variables included in the test. As a consequence, it coincides with twice the number of harmonics included in the Fourier series. We also see the value of each likelihood test (following a $\chi^{2}$ distribution) and their $\mathrm{p}$-value. In bold, we show, according to our analysis, which harmonics are optimal.

Another possibility to test the design of our theoretical model would have been to use another non-parametric process. However, to exploit the possibility of calculating likelihood ratio tests and, in this way, to be able to compare with typical parametric models, we must choose any family within B-splines. In our case, we chose the Chebyshev Polynomials (Sinwell, 2004). However, the results obtained were practically identical. 


\section{Conclusion}

To analyze the influence of existing competition on the probability of voluntary disclosure, it is necessary to take the fact that it is an evolutionary process into consideration. This process goes through different phases according to the sector's maturity. First, fear of proprietary costs generates the typical negative slope between both variables (Verrecchia, 1983). However, when private information loses its strategic nature, this old fear is substituted by indifference, which changes the sign of the relationship (Harris, 1998). This sign continues to be the same despite the fact that indifference is replaced by the incentive to avoid overproduction (Darrough and Stoughton, 1990). And finally, when the sector is clearly at its stage of maximum maturity, it is able to anticipate the significant information which makes voluntary disclosure irrelevant, generating managers' indifference once again (Clinch and Verrecchia, 1997). This reasoning implies a non-monotonic design. In this paper, we have permitted data to speak for itself with no empirical restrictions. We have chosen non-parametric methodologies that have found support for our theoretical reasoning. However, these findings compel us some aspects to be reviewed. For instance, this design facilitates the finding of positive slopes when we adjust linear regressions. This may be the main reason that most of the test has found this sign. However, as the function is non-monotonic, depending on the distribution of data obtained from each sector, it could be to find non-significant tests. In particular, this result is what we have obtained in this paper. In spite of proving that Location Scope Competition has a high level of significance (Pvalue $<0.0000$ ) when we use the appropriate methodology, when we use linear regression all evidence disappears. Thus, not only is it deemed fit to find the correct variables (Ali et al., 2009), but it would also be interesting to apply more sophisticated econometric methods. In any case, 
the real difficulty, due to its shape, is finding negative designs. Previous findings could suggest that these tests did not possess the entire distribution of data.

A second disturbing aspect is the inclusion of several sectors in the same test. Each industry could be at a different stage of maturity and, as a consequence, the results found would be the effect of each sector's random situation in relation to the rest, and not what concerns us, the relationship between competition and voluntary disclosure.

Continuing with this same argument, we consider that each sector has its own idiosyncrasy. In our case, we have found a very symmetrical shape. The height and length of the harmonic's frequency in phases 3 and 4 are very similar to the depth (and length) in phases 1 and 2. In fact, the point of indifference $\lambda$ is located practically in the middle of the range. However, these aspects will depend on the strategic character of the information that we analyze, and of the capability of the sector to forecast this information. In our opinion, a highly technological sector which requires strong investment in research and development and where this information is difficult to replicate or estimate is not the same as a sector where this is not necessary. In both cases, the variability of the harmonic, while respecting the same initial shape, could be very different. Interesting future research could be to compare two or more sectors in relation to their evolution.

The way to measure competition generates several fronts of controversy. We have closed in on several dimensions of competition in our population and we have proven how one measure does not have the slightest level of significance, yet there are others with a degree of significance that is more than interesting. In our opinion, in our case, the non-significant variables are simply not measures of competition in this sector. Newspapers compete with their peers in the same location, thus variables such as Location or Geographic Scope are significant in the test, whereas 
global competition measures, like Broad, or Segment Scope, are meaningless in this industry. If we had not taken this aspect into consideration, we would not have an acceptable measurement. The second open front is in relation to the classification between existing, perceived or expected competition. We have only gathered archival data and, as a consequence, we can only discuss existing competition, not perceived or expected. In relation to perceived competition, our opinion is that it is clear that decision makers take their decisions in relation to what they believe to know. As we only have archival data, we could have found deviations from our theoretical pattern such as the Geographical Scope variable in relation to the initial or final points of indifference. We could have found initial influences of less than one or, on the contrary, final influences greater than one. However, we have the Location Scope variable where deviation in this regard does not exist. Therefore, with the evidence of Location Scope, we believe that in our case, perceived competition is very close to real competition. And addressing the Geographical Scope results, we consider that the deviation is really an error of measurement of the variable and not the difference between existing and perceived competition.

Very similarly, when we speak about ex post competition, we could arrive at similar conclusions; however, as we have found evidence about $\alpha$ and $\omega$ being indifference points with influences similar to one, if there is some deviation caused by expected competition, it should influence the slopes of the relationship within the range of competition while the sector is maturing. It would be very interesting future research if we could split both effects: existing competition, on the one hand, and the effect of expected competition on the other.

\section{Acknowledgements}


We would like to thank Manuel Cano, Salvador Carmona, Juan M. García-Lara, Mahmoud Ezzamel and Flora Muiño for their suggestions. This study was funded by research projects SEJ2007-67582-C02-02 and ECO2010-22105-C03-03 of the Spanish Ministry of Science and Education, and 2008/0059/003 of the Community of Madrid. 


\section{References}

Ali, A., Klasa, S., Yeung, E., 2009. The limitations of industry concentration measures constructed with Compustat data: implications for finance research. The Review of Financial Studies 22, 38393871.

Arya, A., Mittendorf, B., 2005. Using disclosure to influence herd behavior and alter competition. Journal of Accounting and Economics 40, 231-246.

Backer, M., McFarland, W.B., 1968. External reporting for segments of a business. New York: NAA.

Bamber, L.S., Cheon, Y.S., 1998. Discretionary management earnings forecast disclosures: antecedents and outcomes associated with forecast venue and forecast specificity choices. Journal of Accounting Research 36, 167-190.

Bens, D.A., Berger, P.G., Monahan, S.J., 2009. Discretionary disclosure in financial reporting: an examination comparing internal firm data to externally reported segment data. Working Paper, University of Chicago.

Berger, P.G., Hann, R.N., 2007. Segment profitability and the proprietary and agency costs of disclosure. The Accounting Review 82, 869-906.

Botosan, C., Harris, M., 2000. Motivations for a change in disclosure frequency and its consequences: an examination of voluntary quarterly segment disclosures. Journal of Accounting Research 38, 329353.

Botosan, C., Stanford, M., 2005. Managers' motives to withhold segment disclosures and the effect of SFAS no. 131 on analysts' information environment. The Accounting Review 80, 751-771.

Clinch, G., Verrecchia, R.E., 1997. Competitive disadvantage and discretionary disclosure in industries. Australian Journal of Management 22, 125-137.

Cohen, D.A. 2002. Financial reporting quality and proprietary costs. Working Paper, New York University.

Darrough, M., 1993. Disclosure policy and competition: Cournot vs. Bertrand. The Accounting Review $68,534-561$. 
Darrough, M.N., Stoughton, N.M., 1990. Financial disclosure policy in an entry game. Journal of Accounting and Economics 12, 480-511.

Dedman, E., Lennox, C., 2009. Perceived competition, profitability and the withholding of information about sales and the cost of sales. Journal of Accounting and Economics 48, 210-230.

Dye, R.A., Sridhar, S.S., 1995. Industry-wide disclosure dynamics. Journal of Accounting Research 33, $157-174$.

Edwards, P., Smith, R.A., 1996. Competitive disadvantage and voluntary disclosures: the case of segmental reporting. British Accounting Review 28, 155-172

Emmanuel, C.R., Garrod, N., 1987. On the segment identification issue. Accounting and Business Research 17, 235-240.

Ettredge, M.L., Kwon, S. Y., Smith, D.B., 2002. Security market effects associated with SFAS no. 131: reported business segments. Review of Quantitative Finance and Accounting 18, 323-344.

Ettredge, M.L., Kwon, S.Y., Smith, D.B., Stone, M.S., 2006. The effect of SFAS No. 131 on the crosssegment variability of profits reported by multiple segment firms. Review of Accounting Studies $17,91-117$.

Evans, J.H., Sridhar, S.S., 2002. Disclosure-disciplining mechanisms: capital markets, product markets, and shareholder litigation. The Accounting Review 77, 595-626.

Feltham, G.A., Xie, J.Z., 1992. Voluntary financial disclosure in an entry game with continua of types. Contemporary Accounting Research 9, 46-80.

Foster, G., 1986, Financial Statement Analysis. Englewood Cliffs, NJ: Prentice-Hall.

Gigler, F., 1994. Self-enforcing voluntary disclosures. Journal of Accounting Research32, 224-240.

Graham, J.R., Harvey, C.R., Rajgopal, S., 2005. The economic implications of corporate financial reporting. Journal of Accounting and Economics 40, 3-73.

Grossman, S.J., 1981. The role of warranties and private disclosure about product quality. Journal of Law and Economics 24, 461-483.

Harris, M., 1998. The Association between competition and managers' business segment reporting decisions. Journal of Accounting Research 36, 111-128. 
Hayes, R.M., Lundholm, R.J., 1996. Segment reporting to the capital market in the presence of a competitor. Journal of Accounting Research 34, 261-279.

Heitzman,S., Wasley, C., Zimmerman, J., 2010. The joint effects of materiality thresholds and voluntary disclosure incentives on firms' disclosure decisions. Journal of Accounting and Economics 49, 109-132.

Huang, J., 1999. Efficient Estimation of the Partly Linear Additive Cox Model. The annals of Statistics 27, 1536-1563.

Jin, G. Z., 2005. Competition and disclosure incentives: an empirical study of HMOs. Rand Journal of Economics, 36, 93-112.

Klepper, S., 1996. Entry, exit, growth, and innovation over the product life cycle. The American Economic Review, 86, 562-583.

Lawless, J.F., 2003. Statistical Models and Methods for Lifetime Data. New York : J. Wiley.

Leuz, C., 2004. Proprietary versus non-proprietary disclosures: evidence from Germany. In: Leuz, C., Pfaff, D., Hopwood, A. (Eds.). The Economics and Politics of Accounting: International Perspectives on Research Trends, Policy and Practice. Oxford: Oxford University Press, 164-197.

Li, X., 2010. The impacts of product market competition on the quantity and quality of voluntary disclosures. Review of Accounting Studies, in press.

Mautz, R.K., 1968. Financial Reporting by Diversified Companies. Financial Executives Research Foundation, New York.s

Mensah, Y.M., Yang, R., 2008. An empirical evaluation of analysts' herding behavior following Regulation Fair Disclosure. Journal of Accounting and Public Policy 27, 317-338.

Milgrom, P., 1981. Good news and bad news: representation theorems and applications. Bell Journal of Economics 12, 380-391.

Newman, P., Sansing, R., 1993. Disclosure Policies with multiple users. Journal of Accounting Research $31,92-112$ 
Nichols, N.B., Street, D.L., 2007. The relationship between competition and business segment reporting decisions under the management approach of IAS 14 Revised. Journal of International Accounting, Auditing and Taxation 16, 51-68.

Porter, M.E., 1998. Clusters and Competition: New Agendas for Companies, Governments, and Institutions. In “On Competition” Michel E Porter. (Ed). Harvard Business Review Book Series. Boston: 197-287.

Porter, M. E., Millar, V.E., 1998. How information gives you competitive advantage. In “On Competition” Michel E. Porter. (Ed.). Harvard Business Review Book Series. Boston: 75-98.

StataCorp. 2009. Stata: Release 11. Statistical Software. College Station, TX: StataCorp LP.

Shin, Y.C., 2002. The effect of product market competition on corporate voluntary disclosure decisions. Tulane University Working Paper.

Sinwell, B., 2004. The Chebyshev Polynomials: Patterns and Derivation. Mathematics Teacher 98, 20-25.

Verrecchia, R.E., 1983. Discretionary disclosure. Journal of Accounting and Economics 5, 365-380.

Verrecchia, R.E., 1990. Endogenous proprietary costs through firm interdependence. Journal of Accounting and Economics 12, 245-250.

Verrecchia, R.E., Weber, J., 2006. Redacted disclosure. Journal of Accounting Research 44, 791-814.

Wagenhofer, A., 1990. Voluntary disclosure with a strategic opponent. Journal of Accounting and Economics 12, 341-363. 